\title{
A PARTICIPAÇÃO DAS DISCIPLINAS DA ÁREA DE ADMINISTRAÇÃO NOS CURRÍCULOS DOS CURSOS DE BACHARELADO EM GESTÃO AMBIENTAL BRASILEIROS
}

\author{
Luiz Alberto de Lima Leandro \\ luizleandrorj@globo.com \\ Universidade Federal Rural do Rio de Janeiro - Seropédica, RJ / Brasil \\ Camila Avozani Zago \\ camila.avozani@gmail.com \\ Universidade Federal do Rio de Janeiro - Rio de Janeiro, RJ / Brasil
}

http://dx.doi.org/10.1590/1413-2311.0492014.53638

Recebido em 23/09/2014

Aprovado em 29/07/2015

Disponibilizado em 01/08/2015

Avaliado pelo sistema "double blind review"

Revista Eletrônica de Administração

Editor: Luís Felipe Nascimento

ISSN 1413-2311 (versão "on line")

Editada pela Escola de Administração da Universidade Federal do Rio Grande do Sul.

Periodicidade: Quadrimestral

Sistema requerido: Adobe Acrobat Reader.

\section{RESUMO}

Nos últimos anos, os cursos de Gestão Ambiental (GA) vêm formando uma nova classe de gestores/gerentes que, em tese, estão habilitados para administrar as questões relacionadas ao meio ambiente. Embora existam há mais de uma década, tais cursos são pouco conhecidos em termos de estrutura curricular e não possuem Diretrizes Curriculares Nacionais. A discussão sobre a formação dos gestores ambientais brasileiros pode contribuir para situar o curso de GA no contexto da construção da identidade dessa nova categoria profissional. O estudo ora proposto realiza um levantamento das disciplinas presentes nas matrizes curriculares dos cursos de bacharelado em GA, objetivando identificar o peso das diversas áreas do conhecimento, especialmente, da área de administração na construção dessa nova classe profissional, inferindo sobre a concepção da estrutura das Matrizes Curriculares de tais cursos. O procedimento metodológico adotado foi a análise de conteúdo documental que consistiu na verificação do conteúdo das ementas e das matrizes curriculares contidas nos projetos político-pedagógicos (PPP) dos cursos de GA. A despeito do caráter interdisciplinar do curso observa-se significativa participação das disciplinas de Administração na formação dos gestores ambientais brasileiros, confirmada na verificação do conteúdo discursivo dos PPP que apresentam o Gestor Ambiental como um Administrador do meio ambiente. Tal afirmação carece de outros estudos aprofundados sobre a questão das disputas de poder no campo da formação em GA.

Palavras-Chave: Meio Ambiente; Gestor Ambiental; Diretrizes Curriculares Nacionais; Identidade Profissional. 


\author{
PARTICIPATION OF THE DISCIPLINES FROM THE AREA OF \\ ADMINISTRATION IN BRAZILIAN ENVIRONMENTAL MANAGEMENT \\ BACHELOR'S COURSE CURRICULUM
}

\begin{abstract}
In the last years, Environmental Management (EM) courses have come to form a new class of manager that, in theory, are able to administrate issues related to the environment. Although they have been around for more than a decade, such courses are little known in terms of curricular structure and don't have National Curriculum Guidelines. The discussion about the formation of Brazilian environmental managers could contribute to placing the EM course in the context of constructing the identity of this new professional category. This study proposes to pull up the disciplines present in the curricular matrices for EM bachelor's courses, aiming to identify the weights in various areas of knowledge, especially, in the area of administration for the construction of this new class of professional, inferring about the conception of the Curricular Matrix structures of such courses. The methodological procedure adopted was the analysis of the documentary content which consisted in verifying the content of the curricular menus and matrices contained in the pedagogical project policies (PPP) of the EM courses. Despite the multi-disciplinary character of the course, we observed significant participation from the Administration disciplines in training Brazilian environmental managers, confirmed in the discursive content verification of the PPP that present the Environmental Manager as an environmental Administrator. Such statement lacks other more profound studies about the issue of power disputes in the EM field of training.
\end{abstract}

Keywords: Environment; Environmental Manager; National Curriculum Guidelines; Professional Identity.

\title{
LA PARTICIPACIÓN DE LAS DISCIPLINAS DEL ÁREA DE ADMINISTRACIÓN EN LOS TEMARIOS DE LOS CURSOS BRASILEÑOS DE GRADUACIÓN EN GESTIÓN AMBIENTAL
}

\section{RESUMEN}

En los últimos años, los cursos de gestión ambiental (GA) han formado a una nueva clase de gestores que, en teoría, están habilitados para administrar temas relacionados con el medio ambiente. Aunque existan hace más de una década, estos cursos son poco conocidos en términos de estructura de temario y no poseen directrices temáticas nacionales. La discusión sobre la formación de los gestores ambientales brasileños puede contribuir para situar el curso de GA en el contexto de la construcción de la identidad de esta nueva categoría profesional. El estudio propuesto realiza un análisis de las disciplinas presentes en las matrices temáticas de los cursos, con el objetivo de identificar el peso de las diversas áreas de conocimiento, especialmente, del área de administración en la construcción de esta nueva clase profesional, que infieren la concepción de la estructura de las matrices temáticas de estos cursos. El procedimiento metodológico adoptado fue el análisis de contenido documental que se

REAd | Porto Alegre - Edição 81 - N 2 - maio/agosto 2015 - p. 491-514 
constituyó en la verificación del contenido de los resúmenes y de las matrices temáticas contenidas en los proyectos político-pedagógicos (PPP) de los cursos. A pesar del carácter interdisciplinar del curso, se observa una significativa participación de las disciplinas de administración en la formación de los gestores ambientales brasileños confirmada en la verificación del contenido discursivo de los PPP que presentan al gestor ambiental como un administrador del medio ambiente. Tal afirmación carece de otros estudios con profundidad sobre la cuestión de las disputas de poder en el campo de la formación en GA.

Palabras Clave: Medio Ambiente; Gestor Ambiental; Directrices Temáticas Nacionales; Identidad Profesional.

\section{INTRODUÇÃO}

Desde a década de 1960 são realizadas conferências para abordar o impasse vivido por empresas e governos na tentativa de conciliar crescimento econômico e sustentabilidade socioambiental (VEIGA, 2010; SILVA, 2005; MARTÍNEZ ALIER, 2007; SACHS, 2007a; LEFF, 2003; CARNEIRO, 2005; GILBERT, 1995; LITTLE, 2003; ACSELRAD; LEROY, 1999). Visando atender às necessidades de produção, consumo e metas de crescimento econômico, as corporações e o governo (na perspectiva deste artigo o governo brasileiro) buscam desenvolver estratégias tecnológicas e gerenciais para transformar a questão socioambiental em uma variável operacional (AYRES; SIMONIS, 1994; PORTER; VAN DER LINDE, 1996; PORTER, 2011; PORTER; KRAMER, 2011). Nessa perspectiva, a ciência ambiental é convertida em uma ciência gerencial que se propõe a internalizar as externalidades para a obtenção e conciliação de ganhos econômicos e ecológicos.

Historicamente, as universidades assumiram o papel de responsáveis por apresentar soluções para problemas da sociedade oferecendo alternativas através de pesquisas e da formação de profissionais destinados a suprir as demandas públicas e privadas (RIOJAS, 2003).

Em meio às respostas para a tentativa de conciliação entre ganhos econômicos e ecológicos, face aos problemas ambientais que vem sendo observados, principalmente a partir dos dados apresentados nas conferências internacionais sobre meio ambiente desde a década de 1960 (SILVA, 2005; VEIGA, 2010), as Instituições de Ensino Superior (IES) criaram os cursos de bacharelado em Gestão Ambiental. Tais cursos, embora existam há mais de uma década, são pouco conhecidos em termos de estrutura curricular e, por conta de não possuírem Diretrizes Curriculares Nacionais (DCN), não demonstram claro direcionamento em termos de eixos de formação para a consolidação da carreira do gestor ambiental (LEANDRO, 2013).

REAd | Porto Alegre - Edição 81 - N 2 - maio/agosto 2015 - p. 491-514 
A PARTICIPAÇÃO DAS DISCIPLINAS DA ÁREA DE ADMINISTRAÇÃO NOS CURRÍCULOS DOS CURSOS DE BACHARELADO EM GESTÃO AMBIENTAL BRASILEIROS

A despeito desse desconhecimento acerca dos cursos de Gestão Ambiental (GA) estes têm formado uma nova classe de gestores/gerentes que, em tese, estão habilitados para administrar as questões relacionadas ao meio ambiente.

A reflexão sobre a participação das disciplinas oriundas da Administração (Ciência Social Aplicada) nos currículos dos cursos de GA num primeiro olhar pode parecer pequena. Todavia, quando aprofundada, ou pensada no ponto de vista das disputas de poder, tal discussão pode contribuir para situar o curso de Gestão Ambiental no contexto do processo de construção da identidade dessa nova categoria profissional (A questão das disputas de poder no campo da Gestão Ambiental será tratada em outro trabalho, onde a partir dos dados do material levantado neste estudo, combinado a outros materiais, será realizada uma discussão sobre as disputas de sentido e poder na carreira do Gestor Ambiental). A partir dessa reflexão emerge o questionamento: qual a participação das disciplinas de administração enquanto área de conhecimento na formação dos bacharéis em Gestão Ambiental brasileiros? Na perspectiva de responder, mesmo que parcialmente tal questão, este estudo apresenta um levantamento das disciplinas presentes nas matrizes curriculares dos cursos de bacharelado em Gestão Ambiental brasileiros, com vistas a identificar o peso das diversas áreas de conhecimento, especialmente, da área de administração na construção dessa nova classe de profissionais. Além disso, o presente trabalho se propõe a realizar breves inferências sobre essa formação a partir da concepção da estrutura das Matrizes Curriculares de tais cursos.

Este artigo não pretende discutir a questão da influência da administração na formação do gestor ambiental, objetiva introduzir o debate acerca do peso das diversas áreas do conhecimento na formação dos gestores ambientais brasileiros, com vistas a investigações futuras.

\section{PROCEDIMENTOS METODOLÓGICOS}

O procedimento metodológico adotado neste estudo foi a análise de conteúdo quantitativa (FRANCO, 2007; BARDIN, 2010). Tal ferramenta mostrou-se adequada aos objetivos da pesquisa, pois por meio desta é possível realizar inferências sobre o conteúdo (mensagem) de forma verbal (oral ou escrita), gestual, figurativa ou documental. No caso desta pesquisa utilizou-se a análise documental que consistiu na verificação do conteúdo das ementas e das matrizes curriculares contidas nos projetos político-pedagógicos (PPP) dos cursos de Gestão Ambiental, na modalidade bacharelado, oferecidos no Brasil. Para subsidiar as análises que seguem foram utilizados os dados provenientes do trabalho de Leandro REAd | Porto Alegre - Edição 81 - N 2 - maio/agosto 2015 - p. 491-514 
(2013), que forneceu as informações sobre a quantidade de cursos de GA na modalidade bacharelado ofertados no país, as IES onde são oferecidos os cursos e o contato com as coordenações (que possibilitou o acesso aos projetos e às matrizes curriculares).

A partir das informações obtidas foi realizado o levantamento da quantidade de disciplinas oferecidas nos 13 projetos político-pedagógicos dos cursos de bacharelado em GA existentes no país, são eles: Universidade Federal de São Carlos (UFSCAR); Universidade Federal Rural do Rio de Janeiro (UFRRJ); Universidade Federal da Grande Dourados (UFGD); Universidade de Brasília (UNB); Instituto Federal de Goiás (IFG); Universidade do Estado do Rio Grande do Norte (UERN); Universidade Federal do Paraná (UFPR); Universidade Estadual do Rio Grande do Sul (UERGS); Universidade Federal do Pampa (UNIPAMPA); Universidade Federal de Rondônia (UNIR); Universidade Federal do Oeste do Pará (UFOPA); Universidade de São Paulo (USP - Leste) e; Universidade de São Paulo (USP - ESALQ). Observa-se que na USP a formação em GA é ofertada com projetos pedagógicos diferentes (em duas unidades) e por isso, nesta pesquisa, considerou-se que tal IES oferta dois cursos distintos, computando então 13 cursos oferecidos por 12 IES. Cabe destacar que o curso de bacharelado em GA, no Brasil, até a presente data, é ofertado apenas por instituições públicas.

Observa-se que a UERGS não disponibilizou seu PPP para análise das ementas. Neste caso, foi acessada somente a matriz curricular (grade de disciplinas) com a listagem de disciplinas oferecidas. No caso desta IES, considerou-se apenas a nomenclatura das disciplinas para enquadrá-las nas subáreas e eixos de formação. Para os demais cursos foi realizada a leitura das ementas de cada disciplina para categorizá-las nos eixos de formação. Cabe esclarecer, ainda, que a UERGS oferece o curso de bacharelado em GA em cinco unidades diferentes, com a mesma matriz curricular. Como explicitado anteriormente, a USP oferece o curso de GA (bacharelado) com PPP e matrizes curriculares distintas em duas unidades (USP-Leste e USP-ESALQ). Logo, é possível afirmar que há 17 cursos sendo oferecidos, por 12 IES, sendo que há 13 projetos político-pedagógicos (e, por conseguinte, 13 matrizes curriculares) diferentes em andamento na atualidade brasileira no que diz respeito aos cursos de GA oferecidos na modalidade bacharelado.

A análise foi realizada após o levantamento e a categorização das disciplinas em subáreas e eixos de formação, e as inferências realizadas levaram em conta o percentual de cada subárea e área do conhecimento no processo de formação do futuro gestor ambiental, considerando para tal os aspectos nacional, regional, estadual e institucional.

REAd | Porto Alegre - Edição 81 - N 2 - maio/agosto 2015 - p. 491-514 
A PARTICIPAÇÃO DAS DISCIPLINAS DA ÁREA DE ADMINISTRAÇÃO NOS CURRÍCULOS DOS CURSOS DE BACHARELADO EM GESTÃO AMBIENTAL BRASILEIROS

Embora a ferramenta metodológica para o levantamento e categorização das disciplinas seja fundamentada no paradigma quantitativo, as inferências realizadas, em muitos momentos, assemelham-se às realizadas nas análises qualitativas (BARDIN, 2004, MAYRING, 2005; FRANCO, 2007).

\section{O TERMO GESTÃo NA PERSPECTIVA AMBIENTAL}

Concordando com Silva (2006), acredita-se que à medida que as formas de conceber o conhecimento e os processos culturais são alteradas, fazendo emergir qualquer tipo de crise (no caso deste estudo, a problemática socioambiental contemporânea na perspectiva da gestão ambiental). Assim, o currículo e sua materialização, por meio dos PPP, devem ser considerados, essencialmente no interior das instituições de ensino superior, como terreno de disputa de poder e de significado, pois lá se autorizam certos grupos, desautorizam-se outros, conferindo sentidos, construindo e desconstruindo ideias, que, substancialmente, no ensino superior, geram as bases para a formação profissional.

No caso da Gestão Ambiental a questão da disputa ganha destaque porque áreas de conhecimento novas, especialmente as multidisciplinares, que objetivam a formação para atuação profissional, tendem a ser terreno fértil para disputas de poder.

Um ponto importante a ser destacado é que a categoria profissional dos Bacharéis em Gestão Ambiental não possui uma Ordem ou Conselho profissional que regulamente o exercício da profissão (LEANDRO, 2013). Logo, não há diretrizes que possam estabelecer as áreas de atuação ou fiscalização da responsabilidade no exercício profissional. A inexistência de tais entidades, por um lado, facilita a flexibilização na construção das matrizes curriculares no processo de formação dando certa liberdade às IES. Por outro lado, faz com que as relações profissionais dos egressos desses cursos sejam confusas no que diz respeito às áreas e aos limites de atuação, por isso o interesse em verificar o peso de cada eixo de formação, em especial da área da Administração, na formação dos gestores ambientais brasileiros.

Para fundamentar teoricamente as análises que seguem, considera-se relevante clarificar o sentido do termo gestão na esfera do estudo que se processa. Inicia-se a reflexão partindo do significado do termo na língua portuguesa. Fernandes et al (1992) apresenta a palavra gestão como o ato de dirigir, planejar e direcionar. De acordo com as teorias da administração, a gestão abarca a administração com todas as suas funções (FAYOL, 1954; TAYLOR, 1963; STONER; FREEMAN, 1999; DRUCKER, 2002). A observação do seu significado leva a constatação de que a gestão/administração emergiu da necessidade de REAd | Porto Alegre - Edição 81 - N 2 - maio/agosto 2015 - p. 491-514 
organização do trabalho no interior do mercado produtivo industrial - que se acredita ter nascido e crescido a partir da Revolução Industrial.

A necessidade de organização e maximização da produtividade (características da produção capitalista) levou profissionais de outras áreas, especialmente das engenharias, a buscar soluções para as questões advindas da necessidade de aumento da eficiência produtiva industrial. Essa aplicação de métodos oriundos de diversas áreas do saber (por exemplo, psicologia, engenharia, filosofia, sociologia, matemática, entre outras), para administrar estes empreendimentos, ensejou o início das pesquisas e dos estudos administrativos passando, posteriormente, a incluir a administração no elenco das ciências sociais aplicadas (FAYOL, 1954; TAYLOR, 1963; STONER; FREEMAN, 1999; DRUCKER, 2002). Desde então, a gestão/administração se inseriu no contexto de, basicamente, todos os tipos de organizações.

Como o objetivo, nesse momento, é esclarecer o sentido do termo gestão no contexto deste estudo (que está intrinsecamente associado ao conceito de administração) não se deterá em tecer comentários sobre a evolução das teorias administrativas. Para aprofundar o tema sugere-se a leitura de Caravantes et al. (2005), que fornece uma visão geral da evolução das teorias da administração, ao longo do tempo, a partir dos estudos iniciais de Taylor (1963) e Fayol (1954). Sendo assim, concentrar-se-á a atenção na explanação acerca do conceito contemporâneo de gestão, enquanto termo que abarca as funções da administração. Segundo Stoner e Freeman (1999), Graham (2003) e Monin e Bathurst (2008), Mary Parker Follet (1869-1933) foi uma das pioneiras na área de pesquisa em administração. Para esses autores, Follet acreditava que o ato de administrar deveria ser considerado como a arte de desenvolver atividades (organizacionais) com a participação das pessoas rumo ao alcance dos objetivos determinados por aqueles que são responsáveis pelo resultado final da ação empreendida para a consecução dos resultados esperados. Este sentido é adotado até os dias de hoje acrescido das diversas técnicas elaboradas pelas teorias e práticas administrativas.

O conceito contemporâneo de gestão, além de trazer em seu bojo o ato de administrar (com as suas funções: planejar, organizar, dirigir e controlar), também amplia sua esfera de ação, extrapolando a visão empresarial-industrial-capitalista que parece estar contida na compreensão dos críticos da administração enquanto ciência gerencial. No entendimento deste trabalho, além de incorporar elementos da administração, tal conceito assume um sentido mais amplo podendo ser aplicado, desde que intencionalmente, a qualquer tipo de modelo organizacional. Como exemplo, pode-se citar o modelo de gestão adotado pelas organizações 
A PARTICIPAÇÃO DAS DISCIPLINAS DA ÁREA DE ADMINISTRAÇÃO NOS CURRÍCULOS DOS CURSOS DE BACHARELADO EM GESTÃO AMBIENTAL BRASILEIROS

da sociedade civil (OSC), também conhecidas no Brasil como organizações não governamentais (ONG).

Esse conceito de gestão amplo vai ao encontro do propósito dos cursos de gestão ambiental, parte da observação das particularidades de cada região em matéria de população, produção, valores, recursos, necessidades de habitação, saúde, educação e estilos de vida. A Gestão Ambiental parece apontar para a proposta de desenvolvimento que considera a capacidade de suporte e produção de cada região para a viabilização de empreendimentos (empresariais ou públicos) com vistas à promoção da qualidade de vida. Nesse sentido, os resultados desse modelo de desenvolvimento devem ser gerenciados em seus diversos aspectos por gestores capazes de superar as particularidades setoriais observando que seus resultados não estejam comprometidos com uma agenda ambiental que o contradiga.

\section{AS CARGAS HORÁRIAS NO PROCESSO dE CONSTRUÇÃO DOS CURSOS DE GESTÃO AMBIENTAL}

Com a finalidade de dar mais consistência à análise proposta, cabe mencionar que a Lei de Diretrizes e Bases da Educação (BRASIL/LDB, 1996) indica que as IES devem buscar a flexibilização dos seus cursos por meio da diversificação e adequação dos PPP às diversas realidades regionais e institucionais. A despeito desse incentivo à flexibilidade e às adaptações às diferentes realidades, principalmente em um país diverso como o Brasil, o próprio documento define que deve existir um aparato normativo que possa garantir que o processo formativo esteja adequado ao perfil profissional que se quer construir.

Também há a necessidade de garantir que o estudante possa ter mobilidade suficiente para trafegar entre as diversas IES que oferecem o mesmo curso, além de, ao final do processo formativo, poder competir igualitariamente em termos de oportunidades de trabalho, por ter obtido as mesmas bases necessárias ao exercício da profissão (BRASIL/LDB, 1996).

A LDB (BRASIL/LDB, 1996) permite, então, entrever a importância das Diretrizes Curriculares Nacionais (DCN) e também aponta para a necessidade de se observar as cargas horárias dos cursos, num sentido de adequação às realidades educacionais específicas e ao desenvolvimento dos currículos.

O parecer emitido pelo Conselho Nacional de Educação, por meio da Câmara de Educação Superior (CNE/CES N $\left.{ }^{\circ} 8 / 2007\right)$, destaca a razoabilidade da discussão acerca das cargas horárias dos cursos de graduação e da estimativa dos intervalos possíveis para a execução dos mesmos. O cumprimento da carga horária, combinado com a observação das

REAd | Porto Alegre - Edição 81 - Nº 2 - maio/agosto 2015 - p. 491-514 
DCN, orienta o processo de avaliação realizado pelo Ministério da Educação (MEC), seja de forma direta, por meio dos processos de autorização, reconhecimento e renovação dos cursos; seja de forma indireta, como elemento para análise da avaliação institucional e também como parte do Exame Nacional de Desempenho dos Estudantes (ENADE). Diante do exposto, é possível afirmar que as cargas horárias indicadas pelo CNE/CES (2/2007) para os cursos de graduação na modalidade bacharelado, devem funcionar como base para a definição das cargas horárias totais dos cursos que, associadas às DCN e organizadas nas matrizes curriculares no interior dos PPP, estabelecem a organicidade dos cursos que são submetidos à realidade efetiva no decorrer do calendário letivo.

O parecer do Conselho Nacional de Educação (CNE/CES, 184/2006) apresentou a proposta de distribuição de cargas horárias por ano e por dia para os cursos de graduação oferecidos no Brasil, levando em consideração o calendário letivo de 200 dias. A resolução do CNE/CES (8/2007), que dispõe sobre as cargas horárias mínimas e procedimentos relativos à integralização e à duração dos cursos de graduação, bacharelados, na modalidade presencial, classificou os cursos superiores de bacharelado oferecidos no país em grupos (Quadro 1).

Quadro 1 - Quadro de limites para integralização dos cursos de bacharelado presencial - CNE

1) Grupo de Carga Horária Mínima de 2.400 horas =>Limites mínimos para integralização de 3 (três) ou 4 (quatro) anos.

2) Grupo de Carga Horária Mínima de 2.700 horas => Limites mínimos para integralização de 3,5 (três e meio) ou 4 (quatro) anos.

3) Grupo de Carga Horária Mínima entre 3.000 horas e 3.200 horas =>Limite mínimo para integralização de 4 (quatro) anos.

4) Grupo de Carga Horária Mínima entre 3.600 horas e 4.000 horas =>Limite mínimo para integralização de 5 (cinco) anos.

5) Grupo de Carga Horária Mínima de 7.200h: Limite mínimo para integralização de 6 (seis) anos

Fonte: Elaborado a partir da resolução CNE/CES nº 02/2007.

No tocante à exigência de um tempo mínimo para integralização dos cursos de bacharelado em GA, verifica-se que a maioria dos cursos nessa modalidade é ofertada com integralização em 4 anos. Entretanto, embora a média das cargas horárias totais (CHT) gire em torno de 3.165 horas, há cursos oferecidos com 2.790 horas (menor carga horária) e com 3.720 horas (maior carga horária oferecida). Nesses casos, verifica-se uma variação de 


\section{A PARTICIPAÇÃO DAS DISCIPLINAS DA ÁREA DE ADMINISTRAÇÃO NOS CURRÍCULOS DOS CURSOS DE BACHARELADO EM GESTÃO AMBIENTAL BRASILEIROS}

aproximadamente $25 \%$ em termos de CHT dos cursos (diferença entre a maior e a menor CHT). A comparação entre as cargas horárias totais pode ser visualizada no Gráfico 1.

Gráfico 1- Variação das cargas horárias totais (CHT) dos cursos de bacharelado em GA

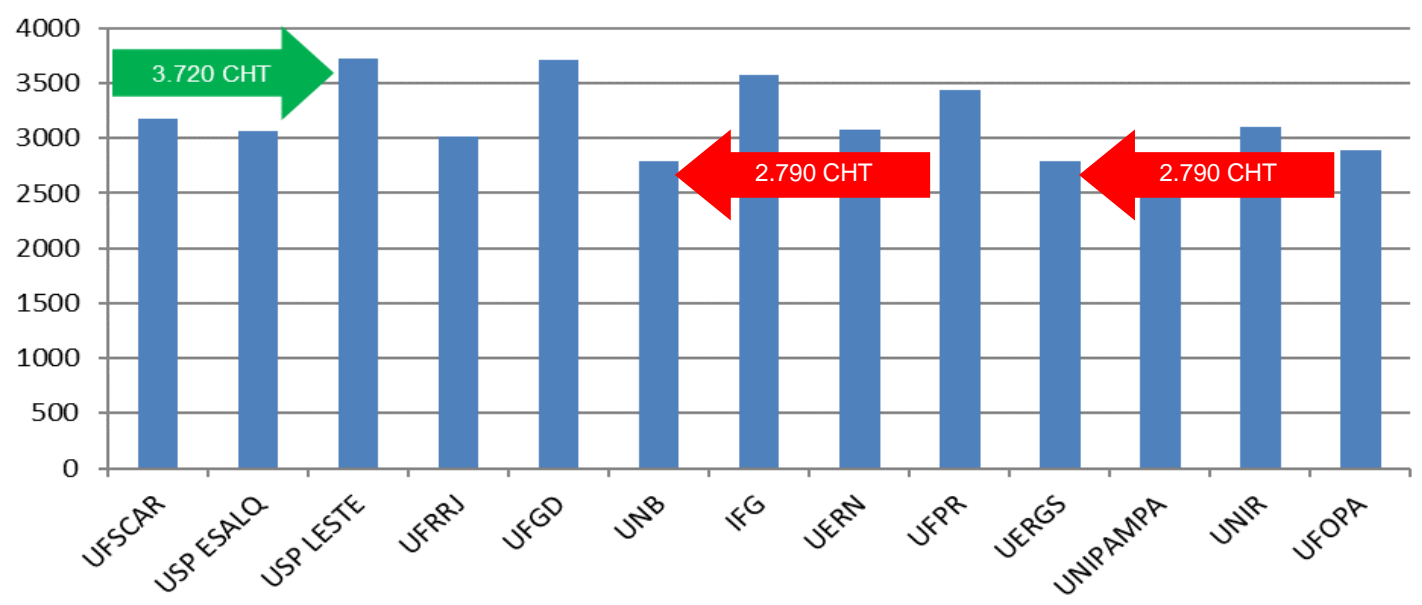

Fonte: Os autores, 2013.

Após analisar todos os cursos de bacharelado em GA na perspectiva da integralização, observando os documentos da CNE/CES (RESOLUÇÃO 2/2007; PARECER 8/2007; PARECER 184/2006), pode-se considerar que esses cursos, quando ofertados com um período de integralização de 4 anos, em turno parcial (diurno ou noturno), deveriam possuir uma CHT que girasse em torno de 3.000 a 3.200 horas, considerando-se as hipóteses de 10\%, $15 \%$ ou $20 \%$ de horas reservadas a estágios e atividades complementares. Isso faria com que os cursos fossem oferecidos com uma carga horária diária de, no máximo, 4 horas/aula/dia.

Segundo o parecer do CNE/CES (8/2007), nenhum curso com carga horária mínima para integralização superior a 3.600 horas teria condições de ser ministrado de forma considerada adequada, no prazo de 4 anos, levando em conta os padrões de qualidade exigidos pelo sistema de avaliação do MEC, se ofertados em turno parcial (diurno ou noturno), havendo condições apenas de serem oferecidos em tempo integral. Caso a IES proponha uma carga horária que seja superior a 3.600 horas, em turno parcial, considera-se necessário que o curso seja integralizado em 5 anos (Tabela 7). Em todos os casos, devem ser consideradas as opções de $10 \%, 15 \%$ e $20 \%$ da CHT destinada ao estágio e às atividades complementares, podendo o curso ser ministrado com uma carga horária diária de, no máximo, 4 horas/aula - para os cursos em turno parcial - sempre considerando o ano letivo de 200 dias. 


\section{INFERÊNCIAS SOBRE A FORMAÇÃO DOS GESTORES AMBIENTAIS NO BRASIL E A RELAÇÃO COM AS DISCIPLINAS DA ÁREA ADMINISTRAÇÃO}

Com a finalidade de dar continuidade à análise proposta neste capítulo (análise quantitativa do conteúdo das matrizes curriculares contidas nos PPP dos cursos de GA) foi estabelecida a seguinte categorização, inspirada nos critérios de classificação das áreas do conhecimento descritos pela CAPES:

1) Áreas - agrupamento de diversas subáreas do conhecimento, fundamentado na afinidade de seus objetos, métodos cognitivos e recursos instrumentais (em determinados momentos, também é utilizada a expressão eixo de formação, quando se refere às áreas do conhecimento aqui descritas);

2) Subáreas - conjunto das disciplinas que possuem similaridade em seus títulos, podendo, com isso, indicar confluência de finalidades de ensino, pesquisa e aplicações práticas;

3) Disciplinas - consistem em um conjunto sistematizado de conhecimentos com características próprias e individuais, que aparecem como unidades de ensino (matérias) no interior das matrizes curriculares (obs.: durante o desenvolvimento desta pesquisa, utilizar-se-á, em alguns momentos, a palavra matéria como sinônimo de disciplina).

Foi desenvolvida, com base nos critérios supracitados, uma tabela de equivalência de disciplinas, utilizando o processador de planilhas Microsoft Excel® em que foram categorizadas, dentro das mesmas subáreas, aquelas matérias que apresentaram similaridade de títulos. Levou-se em conta o conteúdo das ementas, que foram verificados um a um, exceto o caso da UERGS, para a qual o agrupamento levou em consideração apenas a nomenclatura das disciplinas. Todavia, em termos percentuais para a análise em questão, essa classificação por meio da aproximação por nomenclatura foi considerada suficiente. A classificação dos cursos de bacharelado em GA em função das suas áreas (eixos de formação), subáreas e disciplinas pode ser visualizada no Quadro 2. 


\section{A PARTICIPAÇÃO DAS DISCIPLINAS DA ÁREA DE ADMINISTRAÇÃO NOS CURRÍCULOS DOS CURSOS DE BACHARELADO EM GESTÃO AMBIENTAL BRASILEIROS}

Quadro 2 - Classificação das áreas e subáreas de formação em gestão ambiental (bacharelado)

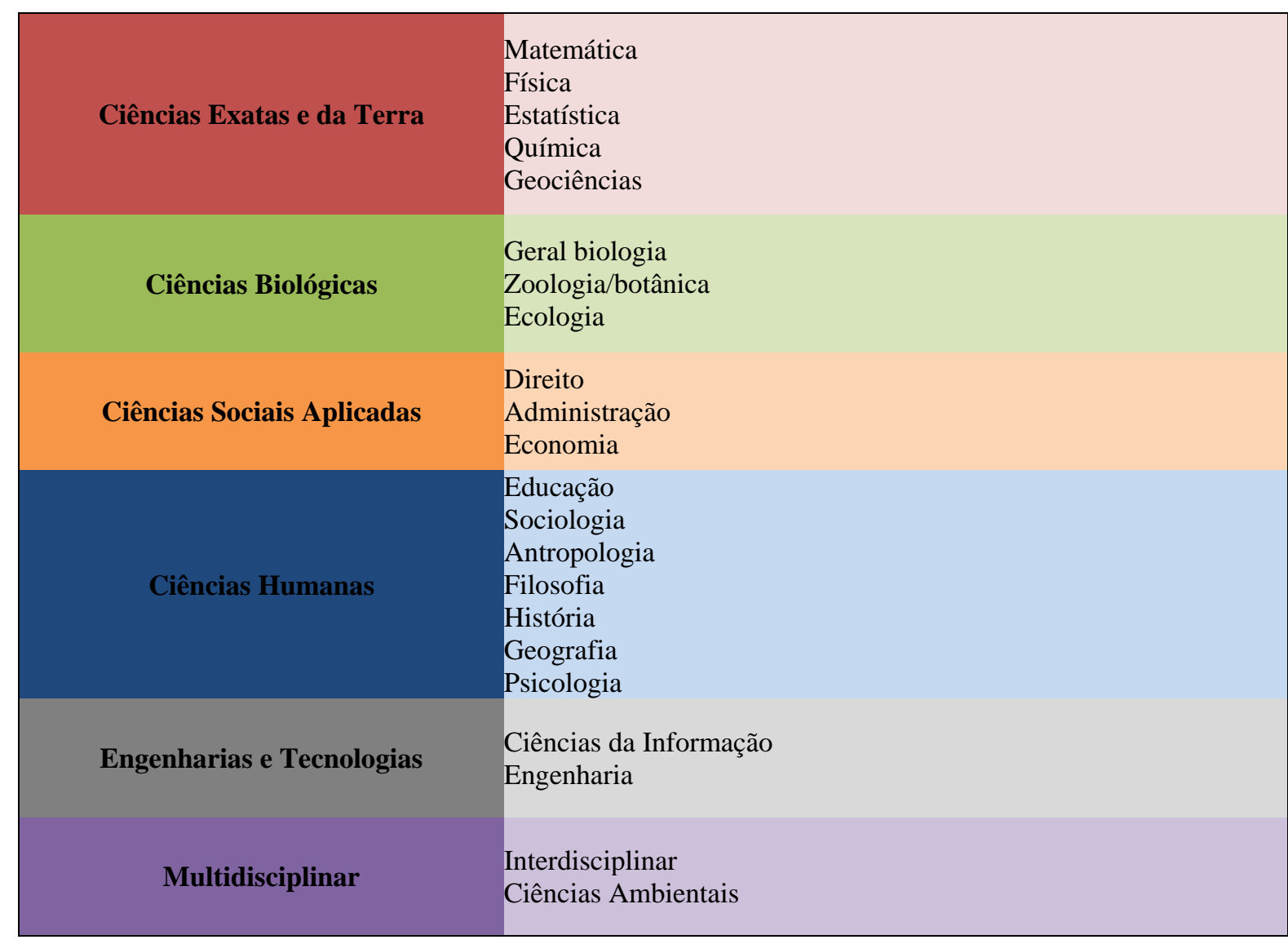

Fonte: Os autores (2013).

A partir da classificação realizada, foi efetuado o somatório das cargas horárias das matérias agrupadas nas respectivas subáreas e calculada a carga horária média de cada uma delas. O objetivo foi, a partir dessa classificação, verificar e apresentar o percentual de cada subárea de estudo na formação discente, o que possibilitou identificar o perfil dos cursos em termos de subáreas (disciplinares) por IES, estado, região e também a nível nacional. As subáreas foram agrupadas em função da afinidade de seus objetos de estudo dentro das áreas. Tal grupamento deu origem ao que foi denominado de eixos de formação (área), os quais permitiram apresentar o peso de cada área (eixo) na formação dos futuros gestores ambientais no Brasil. Tal análise resultou nas tabelas e gráficos que serão apresentados a seguir, nos quais é possível visualizar a concentração das subáreas de conhecimento, das áreas e o peso delas no país por região, estado e IES.

O Gráfico 2 fornece uma visão geral da distribuição das cargas horárias por subárea, o que representa para a formação teórico-prática, em termos disciplinares, aplicada aos cursos 
de bacharelado em GA ofertados no Brasil. Embora o foco tenha sido a matriz curricular foi realizada a leitura flutuante do material discursivo dos PPP para fundamentar as análises deste artigo. Observou-se que todos os cursos afirmam trazer em seus fundamentos o viés interdisciplinar. Ao analisar as disciplinas que deram origem à classificação por subáreas, após a comparação dos títulos e análise dos conteúdos das ementas, verificou-se que as subáreas que possuem as maiores cargas horárias nacionais são classificadas como interdisciplinar e ciências ambientais, seguidas da Administração e posteriormente das demais subáreas.

Gráfico 2 - Cargas horárias médias nacionais por subáreas de formação

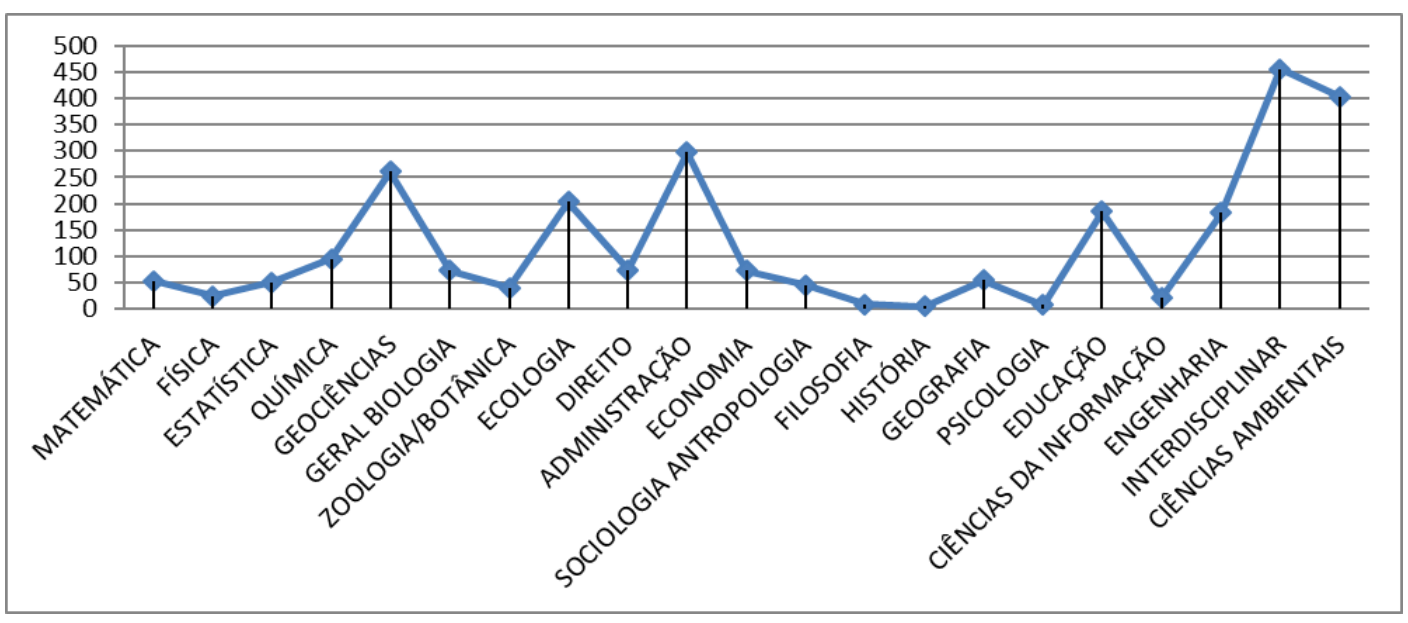

Fonte: Os autores (2013).

Esse ranking demonstra coerência com as propostas de formação teórico-práticoconceituais contidas nos PPP dos cursos, pois as temáticas consideradas essenciais à formação do gestor descritas em tais projetos parecem coadunar-se com o peso das cargas horárias conferidas a tais áreas.

Caminhando na perspectiva dos objetivos deste estudo aponta-se para o fato de que, dentre os projetos analisados, 61\%trouxe nos objetivos e/ou perfil do egresso (parte discursiva do PPP), a afirmação de que os cursos possuem uma relação intrínseca com as Ciências Administrativas, dando à formação em GA um caráter eminentemente gerencial (Quadro 3). 


\section{A PARTICIPAÇÃO DAS DISCIPLINAS DA ÁREA DE ADMINISTRAÇÃO NOS CURRÍCULOS DOS CURSOS DE BACHARELADO EM GESTÃO AMBIENTAL BRASILEIROS}

Quadro 3 - Conteúdos discursivos do PPP que associam a gestão ambiental à administração

\begin{tabular}{|c|c|c|}
\hline \multirow{8}{*}{ 空 } & UNIPAMPA & $\begin{array}{l}\text { O objetivo principal do curso de Bacharelado em Gestão Ambiental na região é } \\
\text { preparar um profissional que terá uma formação básica em ciências ambientais e } \\
\text { administração. }\end{array}$ \\
\hline & UnB & $\begin{array}{l}{[. . .] \text { formar gestores ambientais capazes de criar, realizar e coordenar projetos e }} \\
\text { trabalhos em grupo, com equipes interdisciplinares e multidisciplinares imbuídas da } \\
\text { busca de soluções na Administração e Gestão Ambiental. }\end{array}$ \\
\hline & UFRRJ & $\begin{array}{l}\text { Habilitar os futuros profissionais em temas transversais à questão ambiental, como a } \\
\text { economia, a administração de empresas [...]. Promover estudos de práticas } \\
\text { empresariais e organizacionais que valorizem ações de responsabilidade social e de } \\
\text { sustentabilidade de suas operações. }\end{array}$ \\
\hline & UNIR & $\begin{array}{l}\text { O curso está direcionado para a formação de administradores ambientais } \\
\text { embasados em uma visão holística voltada para a ação [...]. }\end{array}$ \\
\hline & UFGD & $\begin{array}{l}\text { A empresa hoje tem papel fundamental, seja pelo exemplo ao limpar o próprio } \\
\text { quintal, seja como disseminadora de conhecimentos - através da atuação do gestor } \\
\text { ambiental. Neste contexto, o Curso de Gestão Ambiental deve levar em consideração } \\
\text { tanto as perspectivas tradicionais de gerenciamento, bem como as novas demandas } \\
\text { que vêm surgindo nos últimos anos. Para tanto, o curso está direcionado na formação } \\
\text { de administradores ambientais. }\end{array}$ \\
\hline & UERN & $\begin{array}{l}\text { A Gestão Ambiental, procedimento administrativo pautado pela lógica da } \\
\text { sustentabilidade e conduzido através de políticas e ações direcionadas à minimização } \\
\text { dos impactos ambientais provocados pelas sociedades, entrou definitivamente para a } \\
\text { agenda mundial como contraponto à ascensão da estrutura produtiva. Destarte, com } \\
\text { vistas à formação de um profissional na área de Gestão Ambiental que atenda tanto às } \\
\text { demandas empresariais quanto públicas [...]visando à formação de um profissional } \\
\text { com conhecimentos multi, inter e transdisciplinares nas áreas de Administração, } \\
\text { Ciências Ambientais e Ciências Sociais. }\end{array}$ \\
\hline & $\begin{array}{l}\text { USP- } \\
\text { ESALQ }\end{array}$ & $\begin{array}{l}\text { A sua formação profissional é voltada para a administração e procura questionar e } \\
\text { transformar processos organizacionais no sentido da sustentabilidade ambiental. O } \\
\text { curso forma profissionais para atuar na administração, na gestão e no } \\
\text { desenvolvimento de organizações, projetos e atividades específicas da prática } \\
\text { profissional no campo da gestão ambiental. }\end{array}$ \\
\hline & UFOPA & $\begin{array}{l}\text { Para a formação }[\ldots] \text { se faz necessário o estabelecimento de uma base técnico- } \\
\text { científica-educacional acessível a todos os segmentos e atores envolvidos na gestão } \\
{[\ldots] \text {, como forma de subsidiar ações políticas, administrativas e educacionais que }} \\
\text { visem sua exploração sustentável [...] }\end{array}$ \\
\hline
\end{tabular}

Fonte: Os autores (2013).

O perfil gerencial apresenta o gestor ambiental como o administrador do meio ambiente e se manifesta na quantidade de disciplinas oferecidas com conteúdos relacionados às teorias e técnicas da administração. A subárea Administração é a terceira maior em quantidade de horas/aula, sendo superada apenas pelas subáreas Interdisciplinar e Ciências Ambientais, respectivamente, que são compostas por disciplinas de diversas áreas do saber. Ou seja, se for considerada a análise por área disciplinar, pode-se inferir que a Administração é a que apresenta a maior carga horária dentro do curso de Gestão Ambiental, o que corrobora a tese de que a Gestão Ambiental possui relação direta com a Administração, formando um novo tipo de administrador capaz de realizar uma interface entre os projetos causadores de impactos ambientais e a gestão dos negócios em todos os seus níveis.

$$
\text { REAd | Porto Alegre - Edição } 81 \text { - N } 2 \text { - maio/agosto } 2015 \text { - p. 491-514 }
$$


Reforça-se que, por se tratar de uma subárea disciplinar (com conhecimentos advindos da mesma área do saber - a administração científica e seus estudos derivados das diversas teorias da administração), o peso de tal subárea possui maior representatividade, se comparado àquelas que são compostas por grupos de áreas mais difusas (a exemplo do que foi citado anteriormente: Interdisciplinares e as Ciências Ambientais).

Considera-se que, numa perspectiva global, a Administração é a subárea mais expressiva nos cursos de bacharelado de GA de praticamente todas as IES analisadas. O Gráfico 3 apresenta as cargas horárias da subárea Administração, comparadas a outras do mesmo eixo de formação (área).

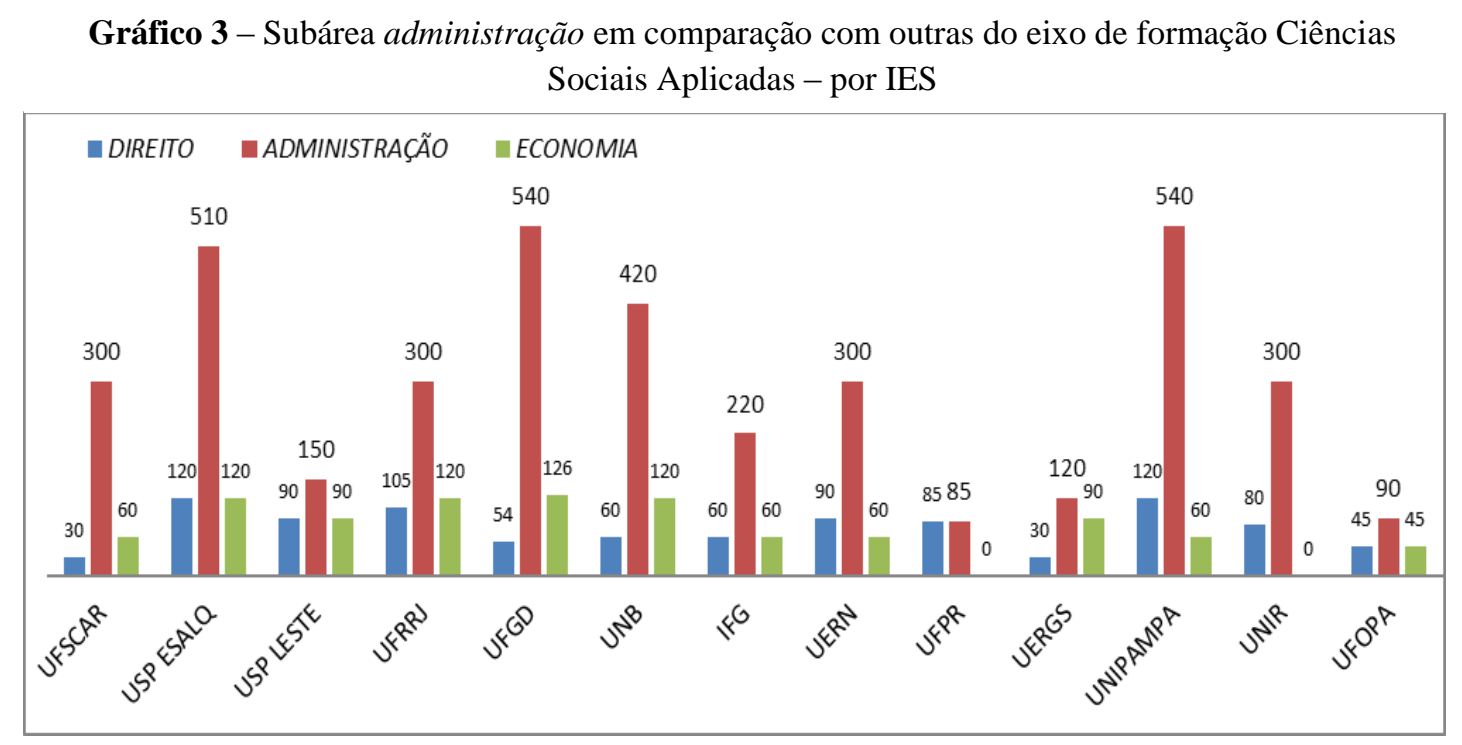

Fonte: Os autores (2013).

Complementando o processo analítico, apontam-se as inconsistências entre as cargas horárias por subárea nos cursos de GA. Verifica-se, por exemplo, que na área das Ciências Exatas e da Terra há diferença significativa na subárea Geociências. A IES que oferece o curso com maior carga horária é a USP-Leste, com 510 horas/aula dedicadas às disciplinas classificadas na referida subárea. A UFPR dedica 85 horas/aula à mesma subárea, o que representa aproximadamente $16,5 \%$ do total de horas/aula oferecido pela USP-Leste. Em termos absolutos, a diferença é de 425 horas/aula, o que aponta para a disparidade na formação do gestor. Cumpre observar que, independente das questões relacionadas às particularidades regionais, tal diferença se mostra bastante significativa se for considerado o aspecto global da formação.

Quando analisado o eixo de formação em Ciências Biológicas dos cursos de bacharelado em GA brasileiros, verifica-se que as diferenças substanciais entre determinadas 
A PARTICIPAÇÃO DAS DISCIPLINAS DA ÁREA DE ADMINISTRAÇÃO NOS CURRÍCULOS DOS CURSOS DE BACHARELADO EM GESTÃO AMBIENTAL BRASILEIROS

subáreas se mantêm. A UFSCAR dedica 480 horas/aula para disciplinas categorizadas na subárea ecologia. A UFRRJ oferta 60 horas para matérias da mesma subárea, o que representa 12,5\% do total oferecido pela UFSCAR. A diferença em horas/aula entre tais subáreas é de 420 horas/aula.

A área de Ciências Humanas também apresentou diferenças consideradas significativas durante o processo analítico. As inferências são iniciadas com a subárea Educação. A diferença entre o curso que possui a maior e a menor quantidade de horas dedicadas a tal subárea é de 695 horas. Sendo a UFPR a IES que oferta a maior quantidade de horas (725 horas/aula) e a USP-Leste a que disponibiliza a menor (30 horas/aula representando $4,1 \%$ da carga horária oferecida pela UFPR). Esse é outro indicador das grandes diferenças entre os cursos de GA na modalidade bacharelado oferecidos no Brasil.

Ao aprofundar a análise, observa-se que houve diferença generalizada nessa subárea entre a UFPR e todas as outras IES que ofertam o curso de bacharelado em GA. Recorre-se a uma análise mais aprofundada da matriz curricular do curso da UFPR e conclui-se que tal carga horária dedicada à subárea Educação ocorre por conta da oferta da série de disciplinas denominada Projeto de Aprendizagem, que é composta de 8 módulos. O projeto possui, em seu fundamento, a ideia de que a educação ocorre de forma processual e toda a objetividade possível é proveniente de uma compreensão de mundo vinculada a determinadas culturas; e a construção do conhecimento é objeto das determinações culturais. Essa série de disciplinas ocorre durante todo o processo formativo e culmina com a construção do trabalho final, no último período, em que o discente apresenta suas experiências e resultados de pesquisas empreendidas durante sua formação ao longo do curso.

Considera-se relevante relatar a experiência da UFPR, pois se observa que, em praticamente todas as IES que oferecem o curso de bacharelado em GA, a subárea Educação possui baixa carga horária, sendo basicamente composta de disciplinas instrumentais (tais como métodos e técnicas de pesquisa) ou da disciplina Educação Ambiental (e suas variações em termos de nomenclatura).

Apenas a UERGS e USP-ESALQ apresentam disciplinas, na subárea Educação, com propostas que envolvem certa integração em termos curriculares na forma de projetos. Todavia, a carga horária dedicada também é pequena (respectivamente 60 e 75 horas/aula), se comparada ao volume de horas/aula dedicado ao mesmo objeto na UFPR. Tal análise pode ser compreendida a partir da observação do Gráfico 4.

REAd | Porto Alegre - Edição 81 - N 2 - maio/agosto 2015 - p. 491-514 
Luiz Alberto de Lima Leandro \& Camila Avozani Zago

Gráfico 4 - Área (eixo de formação) em Ciências Humanas por IES

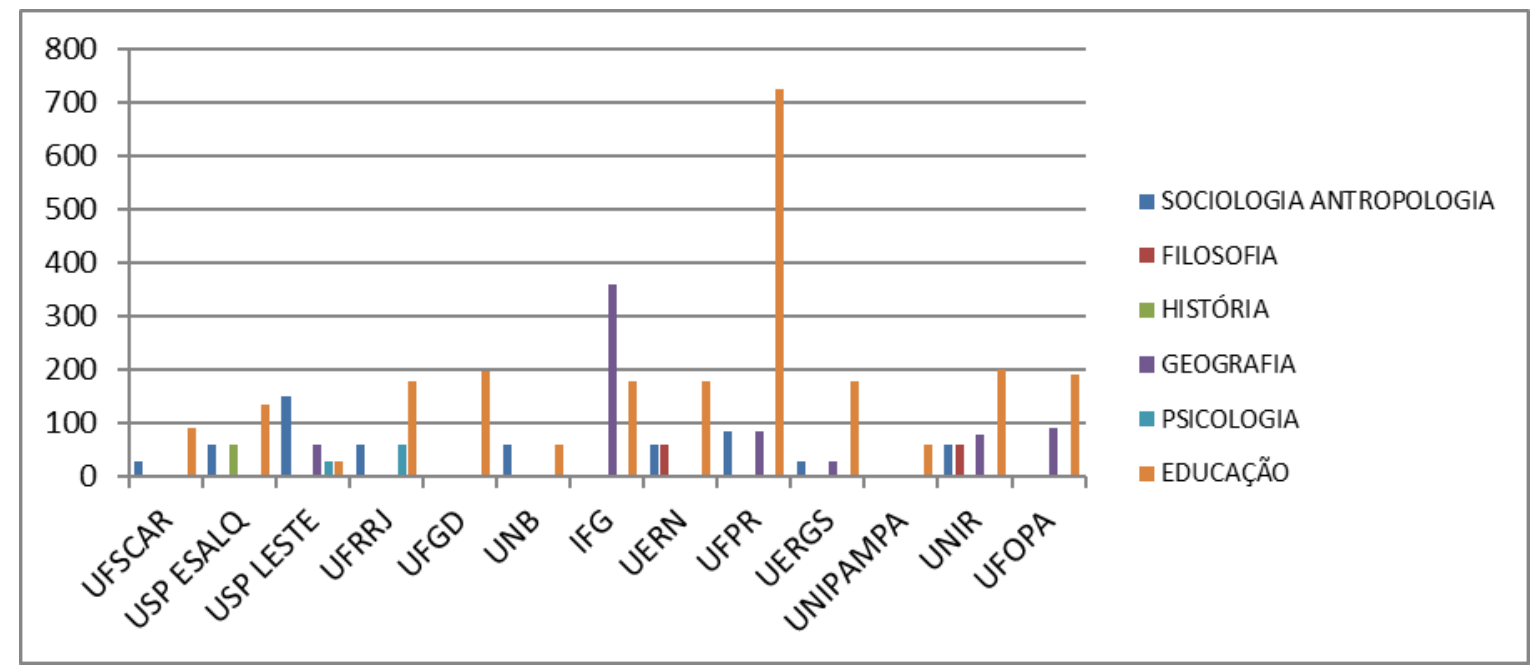

Fonte: Os autores (2013).

A área de formação em Engenharias e Tecnologias apresentou diferença significativa na subárea Engenharia, na comparação entre as IES. A variação entre a maior e a menor quantidade de horas dedicada às disciplinas foi de 570 horas/aula. Sendo que o curso que oferece a menor quantidade de horas representa $5 \%$ em relação ao que oferece a maior quantidade. A menor carga horária na subárea Engenharia é ofertada na USP-ESALQ (uma disciplina com 30 horas) e a que apresenta a maior carga horária é a do curso oferecido pelo IFG, com 600 horas/aula, distribuídas por 12 disciplinas. De uma maneira geral, observa-se que os cursos analisados oferecem uma média relativamente baixa de disciplinas classificadas na subárea Engenharia. O IFG se destaca dos demais, inclusive do segundo lugar (UFOPA), que oferece 420 horas dedicadas às disciplinas da subárea analisada - a diferença entre eles é de aproximadamente $35 \%$.

Embora este estudo se dedique a apresentar a participação das disciplinas da área da Administração nos cursos de GA na modalidade bacharelado oferecidos no Brasil, considerase importante expor o caráter Multidisciplinar dessa formação. Aproximadamente $75 \%$ dos cursos analisados possui grande quantidade de carga horária em horas/aula dedicada a esse eixo de formação. O Gráfico 5 fornece uma visão geral de como ocorre a formação dos gestores ambientais em termos de carga horária disciplinar por eixo de formação. Destaca-se que o curso oferecido pela UERGS, embora apresente equilíbrio na CHT por eixo de formação, é o que apresenta o menor percentual de horas/aula para a área Multidisciplinar. Comparativamente, observa-se que na UERGS apenas $14 \%$ da CHT do curso é dedicada às disciplinas desse eixo de formação, enquanto que na UFPR as disciplinas dessa mesma área correspondem a $46 \%$ da CHT do curso.

REAd | Porto Alegre - Edição 81 - N 2 - maio/agosto 2015 - p. 491-514 


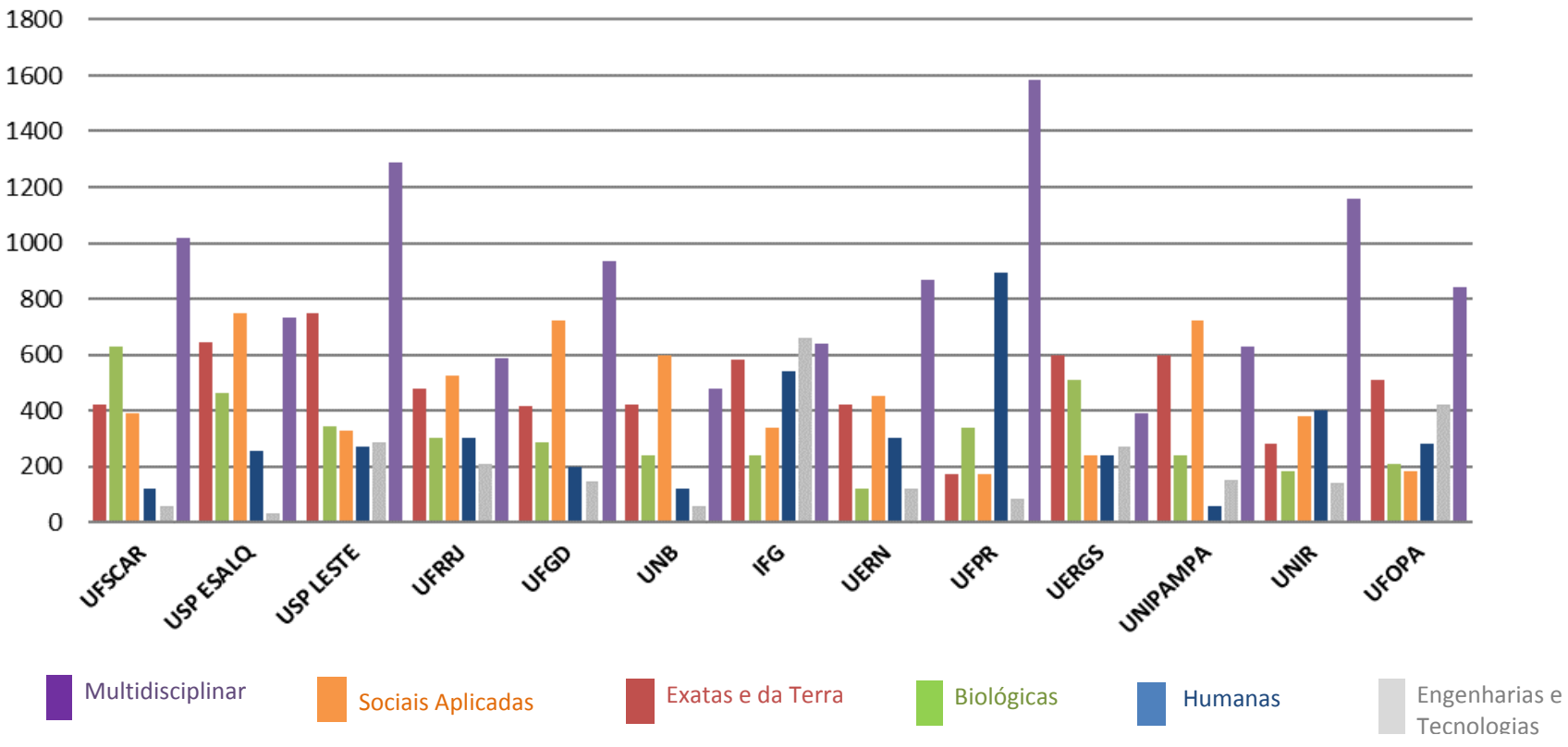

Fonte: Os autores (2013).

No ranking das áreas de formação, embora o curso tenha um viés multidisciplinar, que é, na concepção deste artigo, uma combinação entre as subáreas de Ciências Ambientais e Interdisciplinar, as análises efetuadas confirmam o caráter eminentemente administrativoeconômico-legal. Aponta-se que $17 \%$ da carga horária disciplinar dos cursos de GA brasileiros está orientada para disciplinas nas subáreas de: Administração; Economia;e Direito (apresentadas aqui em ordem de participação de cargas horárias). Nesse contexto, essas três subáreas, que compõem o eixo de formação Ciências Sociais Aplicadas, contribuem de maneira contundente para a construção do arcabouço gerencial do curso. O estudo aponta que tal formação gerencial fornece ao futuro gestor ambiental as habilidades e competências que vão ao encontro da proposta político-pedagógica contida no material discursivo que compõe a maioria dos projetos dos cursos. A observação do Quadro 3, exposto anteriormente, onde as IES apresentam no conteúdo dos projetos político-pedagógicos, complementa a análise quando as IES ressaltam a importância da Administração para a formação do gestor ambiental. Para facilitar a compreensão é apresentado o Gráfico 6 no qual é possível visualizar a presença significativa das disciplinas relacionadas ao arcabouço gerencial dos cursos de bacharelado em GA ofertados no país. 
Luiz Alberto de Lima Leandro \& Camila Avozani Zago

Gráfico 6 - Percentual das áreas (eixos de formação) por região brasileira

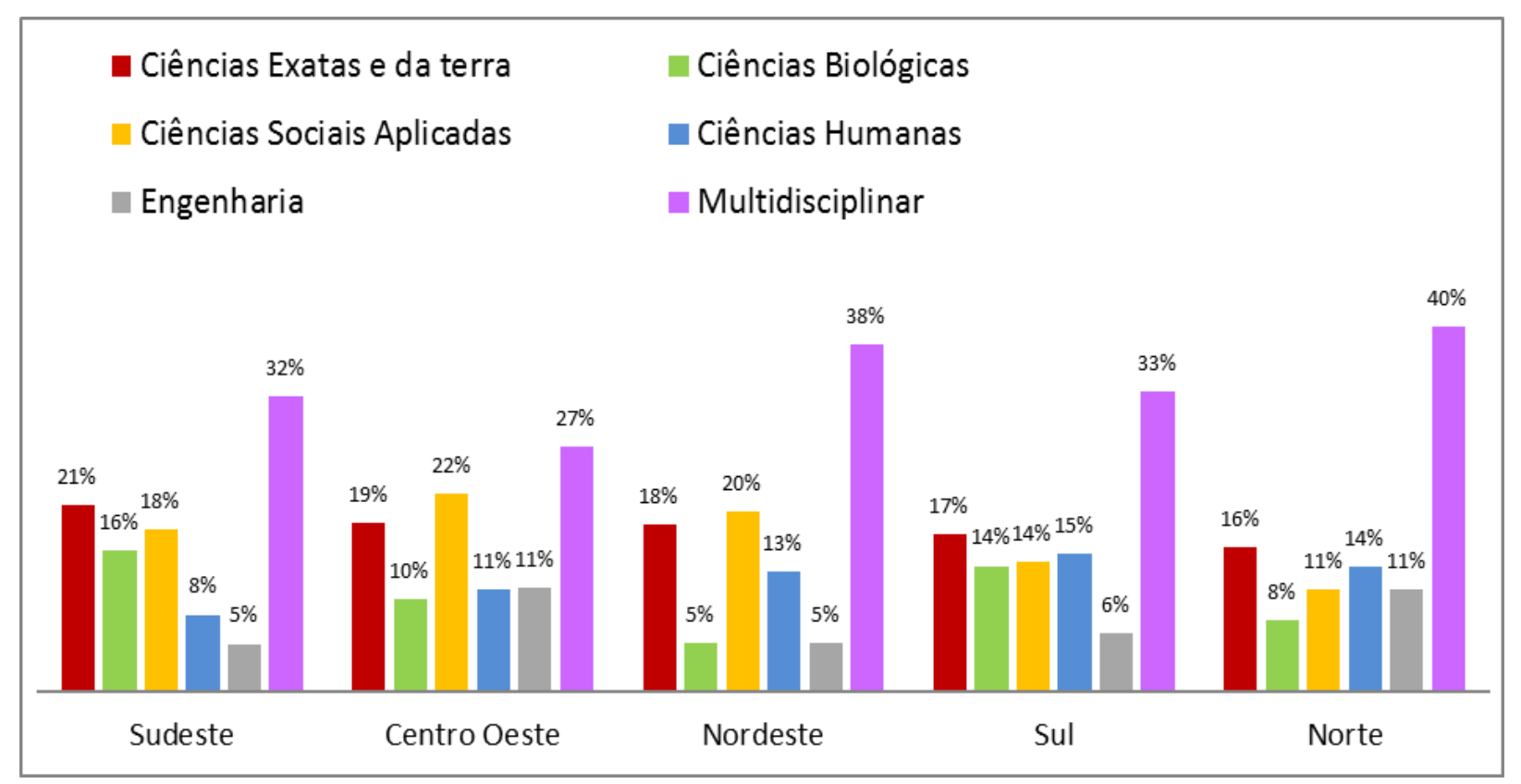

Fonte: Os autores (2013).

Como foi dito ao observar os percentuais nacionais: 18\% Ciências Exatas; $12 \%$ Ciências Biológicas; 17\% Ciências Sociais Aplicadas, 12\% Ciências Humanas; 8\% Engenharias e Tecnologias; e 33\% Multidisciplinar. É possível verificar que em ordem maior carga horária total nos Cursos de GA estão as subáreas Multidisciplinar, seguida de Ciências Exatas e Ciências Sociais Aplicadas, sendo que essa última reforça o caráter gerencial dos cursos analisados em função da quantidade de carga horária dedicada à Administração, foco deste estudo.

\section{CONSIDERAÇÕES FINAIS}

Após concluir as análises das Matrizes Curriculares dos cursos de bacharelado em Gestão Ambiental oferecidos no país, reforça-se a afirmação de que as práticas pedagógicas ocorrem por meio dos currículos e se materializam nos PPP, sendo operacionalizadas na aplicação das matrizes curriculares.

As matrizes são muito mais do que a mera distribuição dos conteúdos disciplinares ao longo dos períodos letivos. O processo de construção e operacionalização do currículo consiste também na disputa de sentidos, na constituição de valores para a criação de uma identidade profissional. Neste caso, o que está em questão é o peso/participação das disciplinas da área de Administração nos cursos de GA brasileiros, o que, na visão deste 
A PARTICIPAÇÃO DAS DISCIPLINAS DA ÁREA DE ADMINISTRAÇÃO NOS CURRÍCULOS DOS CURSOS DE BACHARELADO EM GESTÃO AMBIENTAL BRASILEIROS

artigo, retira o aspecto puramente biológico associado a nomenclatura do curso e, por conseguinte, dos profissionais formados.

No processo analítico das cargas horárias disciplinares verifica-se que, a despeito da exigência de um tempo mínimo para integralização dos cursos de bacharelado em GA, a maior parte dos projetos político-pedagógicos propõe o período de 4 anos como mínimo para integralização, mesmo possuindo cargas horárias totais que apresentem variações entre si de aproximadamente $30 \%$. Quando procedida a análise do contexto social, dos objetivos (geral e específicos) e do perfil profissional descritos nos PPP, verifica-se que a proposta interdisciplinar fundamentou os currículos. Algo que é considerado coerente com a proposta dos cursos.

Ao realizar a classificação das disciplinas que deram origem às subáreas, conclui-se que a subárea que possui maior carga horária no curso (nacionalmente) é a classificada como interdisciplinar. Quando consideradas as cargas horárias disciplinares por eixo de formação (áreas) nas regiões brasileiras, verifica-se que a informação de que os cursos possuem, ao menos em termos de carga horária, um perfil eminentemente multidisciplinar se mantém, pois, a área Multidisciplinar, que é composta pelas subáreas interdisciplinar e ciências ambientais, apresenta a maior carga horária disciplinar oferecida nacionalmente.

Dos 13 cursos analisados neste trabalho, apenas o curso ofertado pelo IFG apresenta o conteúdo dedicado ao eixo de formação Engenharias e Tecnologias com carga horária ligeiramente maior - cerca de $4 \%$ mais elevada do que a área Multidisciplinar. Na esteira dessa análise, verifica-se que os cursos de bacharelado apresentam, num aspecto global, uma forte orientação para as Ciências Exatas, sendo $18 \%$ da carga horária disciplinar dos cursos ofertados no país é dedicada à essa área.

A despeito áreas Multidisciplinar e Ciências Exatas, observa-se que, em termos disciplinares, os cursos apresentam um caráter eminentemente gerencial, que se manifesta na quantidade de disciplinas oferecidas que possuem conteúdos relacionados às teorias e técnicas da administração. Esse perfil gerencial se confirma quando associado a outras subáreas, que compõem o eixo de formação Ciências Sociais Aplicadas, que ampliam a formação gerencial, conferindo ao curso um viés administrativo-econômico-legal. Importa ressaltar que $17 \%$ da carga horária disciplinar dos cursos de GA brasileiros está orientada, em ordem de prioridade, para disciplinas nas subáreas de: administração; economia; e direito. Aponta-se para a existência de 43 disciplinas presentes nesse eixo de formação, excluindo-se aquelas da subárea do direito.

REAd | Porto Alegre - Edição 81 - N 2 - maio/agosto 2015 - p. 491-514 
Luiz Alberto de Lima Leandro \& Camila Avozani Zago

Dessa forma, percebe-se o grande peso e participação das disciplinas de Administração na formação dos gestores ambientais brasileiros, sendo que esse perfil gerencial se confirma quando se verifica no conteúdo discursivo dos projetos políticopedagógicos: aproximadamente $60 \%$ dos projetos apresenta o gestor ambiental como o administrador do meio ambiente. Tal afirmação merece reflexão, pois é preciso ter cuidado para que a ação em prol dos interesses privados não priorize a gestão mercadológica, considerando que somente por meio da atuação administrativa eficiente e eficaz se consiga promover o desenvolvimento que possa ser considerado sustentável.

\section{REFERÊNCIAS}

ACSELRAD, H.; LEROY, J. Novas premissas da sustentabilidade democrática. Rio de Janeiro: FASE, 1999.

AYRES, R.U; SIMONIS, U.E. Industrial metabolism: theory and policy. In: AYRES, R.U; SIMONIS, U.E (orgs.). Industrial metabolism: restructuring for sustainable development. Tokyo: United Nation University Press, 1994.

BARDIN, L. Análise de conteúdo.Lisboa: Edições 70, 2010.

BRASIL. Câmara dos Deputados. Lei no 9.394, de 20 de dezembro de 1996. LDB - Lei de Diretrizes e Bases da Educação Nacional,Brasília, DF, Publicada no Diário Oficial da União, Seção 1, de 23 de dezembro de 1996, p. 27833.

CARAVANTES, G. R. et. al. Administração: teorias e processos. São Paulo: Pearson Prentice Hall, 2005.

CARNEIRO, E. J. Política Ambiental e a ideologia do desenvolvimento sustentável. In: ZHOURI, A.; KLEMENS, L.; PEREIRA, D. B. (org.). A insustentável leveza da política ambiental: desenvolvimento e conflitos socioambientais. Belo Horizonte: Autêntica, 2005.

\section{CONSELHO NACIONAL DE EDUCAÇÃO/CÂMARA DE EDUCAÇÃO SUPERIOR.}

Parecer 8/2007 de 31 de janeiro de 2007. Dispõe sobre carga horária mínima e procedimentos relativos à integralização e duração dos cursos de graduação, bacharelados, na modalidade presencial. Disponível em:

http://portal.mec.gov.br/cne/arquivos/pdf/2007/pces008_07.pdf. Acesso em: maio, 2013.

CONSELHO NACIONAL DE EDUCAÇÃO/CÂMARA DE EDUCAÇÃO SUPERIOR. Resolução 2/2007 de 18 de junho de 2007. Dispõe sobre carga horária mínima e

REAd | Porto Alegre - Edição 81 - N 2 - maio/agosto 2015 - p. 491-514 
A PARTICIPAÇÃO DAS DISCIPLINAS DA ÁREA DE ADMINISTRAÇÃO NOS CURRÍCULOS DOS CURSOS DE BACHARELADO EM GESTÃO AMBIENTAL BRASILEIROS

procedimentos relativos à integralização e duração dos cursos de graduação, bacharelados, na modalidade presencial. Disponível em:

http://portal.mec.gov.br/cne/arquivos/pdf/2007/rces002_07.pdf. Acesso em maio, 2013.

CONSELHO NACIONAL DE EDUCAÇÃO/CÂMARA DE EDUCAÇÃO SUPERIOR. Parecer 184/2006 de 07 de julho de 2006. Retificação do Parecer CNE/CES nº 329/2004, referente à carga horáriamínima dos cursos de graduação, bacharelados, na modalidade presencial. Disponível em: http://www.unb.br/administracao/decanatos/dex/formularios/Documentos\%20normativos/DE X/pces0184_06.pdfAcesso em maio, 2013.

DRUCKER, F. P.Introdução à administração. 3. ed. São Paulo: Pioneira Thompson Learning, 2002.

FAYOL, H. Administração industrial e geral. São Paulo: Atlas, 1954.

FERNANDES, F. et al. Dicionário Brasileiro Globo. 25 ed. São Paulo: Ed. Globo, 1992.

FRANCO, M.L.P.B. Análise de conteúdo. 2 ed. Brasília: Liber Livro Editora, 2007.

GILBERT, A. Third world: poverty, employment and gender roles during a time of restructuring. In: D’AVILA, Maria Inácia (coord.) UNESCO Chair on Sustainable Development. Social development:challengesandstrategies. Rio de Janeiro: UFRJ/UNESCO, 1995.

GRAHAM, P. Mary Parker Follet prophet of management - A celebration of writings from de 1920s. Washington DC: Beard Books-Harvard Business School Press, 2003.

LEANDRO, L.A.L. A formação superior dos gestores ambientais no Brasil: contribuição para a formulação de diretrizes curriculares nacionais.2013. 330 p. Tese de Doutorado. Universidade do Estado do Rio de Janeiro, Rio de Janeiro.

LEFF, E. Pensar a complexidade ambiental. In: LEFF, Enrique (org). A complexidade ambiental.Blumenau: Cortez / Edifurb, 2003.

LITTLE, P. E. Políticas ambientais no Brasil: análises, instrumentos e experiências. São Paulo: Peirópolis; DF: IIEB, 2003. 
MARTÍNEZ-ALIER, J. O ecologismo dos pobres: conflitos ambientais e linguagem de valoração. São Paulo: Contexto, 2007.

MAYRING, P. Einführung in die qualitativeSozialforschung [Introdução à pesquisa social qualitativa]. 5 ed.Weinheim: Beltz, 2002. Disponível em: http://www.unb.br. Acesso em: abril, 2005.

MONIN, N; BATHURST, R. Mary Follett on the Leadership of 'Everyman' In: Ephemera theory \& politics in organization. v. 8, n. 4, pp. 447-46, 2008. Disponível em:

http://www.ephemerajournal.org/sites/default/files/8-4monin-bathurst.pdf. Acesso em abril, 2013.

PORTER, M.; VAN DER LINDE, C. Green and Competitive: Ending the Stalemate. In: PORTER, M. E. On Competition. The Harvard Business Review book series. Boston: Harvard Business School Publishing, 1998.

PORTER, M. E.; KRAMER, M. R. Creating shared value - How to reinvent capitalism-and unlash a wave of innovation and growth. Harvard Business School, Jan-fev. 2011.

PORTER, M. O Capitalismo do valor compartilhado. HSM Management. Barueri, n. 88, ano 15, vol. 5, p. 42-48, set-out. 2011.

RIOJAS, J. A complexidade ambiental na universidade. In: LEFF, Enrique (org). A complexidade ambiental. Blumenau: Cortez / Edifurb, 2003.

SACHS, I. A revolução energética do século XXI. Estudos avançados. São Paulo, v. 21, n. 59, Abr. 2007 . Disponível em:

http://www.scielo.br/scielo.php?script=sci_arttext\&pid=S0103-

40142007000100004\&lng=en\&nrm=iso. Acesso em maio, 2011.

2007.

Rumo à ecossocioeconomia - Teoria e prática do desenvolvimento. São Paulo: Cortez,

SILVA, J.C.T. et al. Correlação entre gestão da tecnologia e gestão ambiental nas empresas. Produção, São Paulo, v. 15, n. 2, ago. 2005 . Disponível em http://www.scielo.br/scielo.php?script=sci_arttext\&pid=S0103-

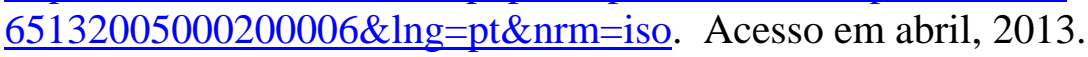

SILVA, T. T. O currículo como fetiche:a poética e a política do texto curricular. 3 ed. Belo Horizonte: Autêntica, 2006. 
A PARTICIPAÇÃO DAS DISCIPLINAS DA ÁREA DE ADMINISTRAÇÃO NOS CURRÍCULOS DOS CURSOS DE BACHARELADO EM GESTÃO AMBIENTAL BRASILEIROS

Documentos de identidade:uma introdução às teorias do currículo. 3 ed. Belo Horizonte: Autêntica, 2009.

STONER; J.A.F.; FREEMAN, R.E. Administração. 5. ed. Rio de Janeiro: LTC, 1999.

TAYLOR, F. W. Princípios de administração científica. São Paulo: Atlas, 1963.

VEIGA, J.E. Desenvolvimento sustentável:o desfio do século XXI. Rio de Janeiro: Garamond, 2010. 